\title{
A Study of Fault Diagnosis Based on Electrical Signature Analysis for Synchronous Generators Predictive Maintenance in Bulk Electric Systems
}

\author{
Camila Paes Salomon ${ }^{1}{ }^{(}$, Claudio Ferreira $^{1}$, Wilson Cesar Sant'Ana ${ }^{2}{ }^{\mathbb{D}}$, \\ Germano Lambert-Torres ${ }^{2, *(1)}$, Luiz Eduardo Borges da Silva ${ }^{3}$, Erik Leandro Bonaldi ${ }^{2}$, \\ Levy Ely de Lacerda de Oliveira ${ }^{2}$ and Bruno Silva Torres ${ }^{1}$ \\ 1 Institute of Electric Systems and Energy, Itajuba Federal University, Itajuba 37500-903, Brazil; \\ camilapsalomon@gmail.com (C.P.S.); claudiof@unifei.edu.br (C.F.); \\ brunotorres@institutognarus.com.br (B.S.T.) \\ 2 Gnarus Institute, Itajuba 37500-052, Brazil; wilson.cesar.santana@gmail.com (W.C.S.); \\ erik@pssolucoes.com.br (E.L.B.); levy@pssolucoes.com.br (L.E.d.L.d.O.) \\ 3 Institute of System Engineering and Information Technology, Itajuba Federal University, Itajuba 37500-903, \\ Brazil; leborgess@gmail.com \\ * Correspondence: germanoltorres@gmail.com; Tel.: +55-35-99-986-0378
}

Received: 6 March 2019; Accepted: 18 April 2019; Published: 21 April 2019

\begin{abstract}
The condition of synchronous generators (SGs) is a matter of great attention, because they can be seen as equipment and also as fundamental elements of power systems. Thus, there is a growing interest in new technologies to improve SG protection and maintenance schemes. In this context, electrical signature analysis (ESA) is a non-invasive technique that has been increasingly applied to the predictive maintenance of rotating electrical machines. However, in general, the works applying ESA to SGs are focused on isolated machines. Thus, this paper presents a study on the condition monitoring of SGs in bulk electric systems by using ESA. The main contribution of this work is the practical results of ESA for fault detection in in-service SGs interconnected to a power system. Two types of faults were detected in an SG at a Brazilian hydroelectric power plant by using ESA, including stator electrical unbalance and mechanical misalignment. This paper also addresses peculiarities in the ESA of wound rotor SGs, including recommendations for signal analysis, how to discriminate rotor faults on fault patterns, and the particularities of two-pole SGs.
\end{abstract}

Keywords: bulk electric system; condition monitoring; electrical signature analysis; fault diagnosis; predictive maintenance; synchronous generator

\section{Introduction}

Electrical power systems consist of a large number of interconnected synchronous generators (SGs) operating in parallel, connected to transmission and distribution networks to supply large load centers. These machines are fundamental elements of power systems, and their condition affects network reliability and stability [1]. The parallel operation of SGs presents several advantages such as the increase of supply reliability, the improvement of efficiency, and lower cost. However, it increases the complexity of the stability control of the SGs when a fault occurs [2]. Thus, there is a growing interest in new technologies to improve SG protection and maintenance schemes [3-5].

Among the maintenance philosophies that have been applied to SGs, condition-based maintenance (CBM) is highlighted. This type of maintenance is based on the continuous monitoring of a condition parameter in a machine (vibration, temperature, electrical signals, etc.) [6]. CBM consists of the analysis of the monitored parameters to evaluate if certain indicators present signs of decreasing performance 
or incipient fault. Thus, the actual condition of the asset is evaluated, and it is possible to decide what and when the maintenance action must be done [7].

In the context of CBM, electrical signature analysis (ESA) has been increasingly applied to rotating electric machines fault diagnostics. In ESA, the monitored parameters are the electrical signals of the machine in the frequency domain. This is performed by using a Fast Fourier Transform (FFT) algorithm and other signal processing procedures. The faults are detected and identified by analyzing fault patterns on voltage and current spectra, which are frequency components whose magnitudes vary when a fault happens. Moreover, faults can be detected at an early stage and the frequency components' magnitudes are generally related to the fault severity. The main advantages of ESA are no intrusiveness, dependence on only electrical quantities, technical and economic viability, and possibility of obtaining fault patterns applicable for all types of wound rotor SGs [6,8-10].

There are several published works about ESA-based methodologies for fault detection in synchronous machines. ESA has been used mainly for detection of stator winding inter-turn short circuit [11-16], rotor winding inter-turn short circuit [11,13,17-20], air-gap eccentricity [21-25], and rotating diode failure [26,27]. There are also works approaching various electrical and mechanical faults in SGs [28].

Despite the increasing use of ESA in CBM, it is important to highlight that some particularities arise when this technique is applied to SGs. Firstly, the choice of signals to be analyzed must be considered, because both current and voltage are outputs of these machines. There is also an issue related to faults that coincide in the same fault pattern. For instance, the rotor rotation frequency fault pattern is indicative of rotor winding inter-turn short circuit and rotor mechanical faults $[9,11,13,19,29]$. Thus, the analysis of only the rotation frequency components allows the detection of rotor problems. However, this is not sufficient to identify the type of fault (electrical or mechanical). There is also an issue related to two-pole type SGs. In these machines, the rotor rotation frequency matches the power line frequency. Therefore, the fault patterns and the power system harmonics match the same components. Thus, the ESA-based fault diagnostic can be obscured because of the SGs intrinsic harmonics or harmonics related to non-linear loads [30-34]. Finally, in general, the works found in literature present ESA application to isolated SGs, both in a laboratory environment and in SGs onboard ships $[13,15,24]$. However, large SGs are usually interconnected to power systems, so ESA should also be applied to SGs in this condition.

Given this scenario, this paper presents a study on fault diagnosis of SGs in bulk electric systems using ESA. Firstly, a methodology for SG fault detection using ESA is proposed, addressing ESA fault patterns and the mentioned peculiarities of this technique for fault detection in SGs. Then, as the main contribution of this work, case studies of fault detection using ESA in an in-service SG in a Brazilian hydroelectric power plant are presented. The results show the potential of ESA for condition monitoring of SGs interconnected to power systems and are valuable, since SGs in this context are concerned with monitoring and are subjected to diverse conditions of the bulk power system. As mentioned previously, other works usually present results in a laboratory environment with isolated SGs and controlled conditions, which do not fully depict the SGs in practical situations.

As a note, it is known that SGs conditions might include normal condition, oil-membrane oscillation, imbalance, no orderliness, short circuit, and so on. However, this work focuses on conditions covering healthy and faulty situations, including fault detection and identification. Moreover, it is worth noting that artificial intelligence-based methodologies have been increasingly applied to rotating machinery fault detection and condition monitoring nowadays [35-37]. These techniques can be used in future works as auxiliary tools to complement the fault diagnosis by using the proposed methodology, being not in the scope of the present work.

The rest of the paper is divided as follows. Section 2 presents the ESA background. Section 3 presents ESA fault patterns for SGs. Section 4 approaches the peculiarities of ESA application to SGs. Section 5 presents the proposed methodology for fault detection in SGs in interconnected power 
systems. Section 6 presents results of fault detection in SG in a power plant. Finally, Section 7 presents the conclusions.

\section{Electrical Signature Analysis Background}

ESA consists of the frequency-domain representation, processing, and analysis of electrical signals and has been usually applied in electric machinery condition monitoring. In general, ESA comprises of an FFT (Fast Fourier Transform) algorithm to represent the time-domain signals in the shape of spectra, which are referred in this work as electrical signatures. ESA is based on the assumption that a significant change in a machine condition results in the change of its electrical signature. Moreover, there are specific frequency components whose magnitudes change in the presence of faults. These frequency components are related to the type and location of fault, being dependent on the power line frequency and structural characteristics of the motor or generator. Thus, it is possible to obtain a set of ESA fault patterns for fault detection and identification in electrical machines [38]. Moreover, the fault patterns can be applicable to all types of wound rotor SGs.

The ESA techniques used in this work are current (CSA) and voltage signature analysis (VSA), and extended Park's vector approach (EPVA), which will be explained in the next sections.

\subsection{Current and Voltage Signatures}

CSA and VSA consist purely of the frequency-domain analysis of the current and voltage signals from the machine stator. The electrical signatures are obtained through the application of FFT to voltage and current signals. FFT is an algorithm with the purpose of computing the Discrete Fourier Transform (DFT) in a faster way. Considering a list of complex numbers, the DFT transforms that into a list of coefficients of a finite combination of complex sinusoids. Each DFT component is given by [39]:

$$
X_{m}=\sum_{n=0}^{N-1} x_{n} \cdot e^{-j 2 \pi m n / N}, m \in Z
$$

where $m$ is the DFT index (harmonic order), $n$ is the time-domain index, $N$ is the number of samples, $X_{m}$ is the $m^{\text {th }}$ DFT coefficient, and $x_{n}$ is the time-domain list of equally-spaced complex samples.

FFT decomposition allows the determination of the magnitude and the phase of each frequency component of the electrical signal under analysis. As mentioned previously, these components can compose a set of fault patterns for machine diagnosis, and generally the magnitudes of these components increase according to the fault severity.

In practice, the spectral components' magnitudes are usually presented normalized in relation to the fundamental component magnitude (line frequency), due to the changes of current in function of load. Moreover, the use of a logarithm scale (in general, $\mathrm{dB}$ ) is common, because of the big difference between the magnitudes and the exponential characteristic of the evolution presented for several known faults [7].

In general, the fault components are expressed in the frequency spectrum as:

$$
f_{e}=f_{1} \pm k \cdot f_{c}
$$

where $f_{e}$ is the fault frequency as it appears in the spectrum, considering the power line frequency modulation; $f_{1}$ is the power line frequency; $k$ is a positive integer value, indicating the harmonic order; and $f_{\mathcal{C}}$ is the specific fault characteristic frequency.

\subsection{Extended Park's Vector Approach}

EPVA is a technique based on a quantitative analysis of the Park circle distortion, whose main characteristic is considering information of the three phases of electrical signals. It is specifically used 
as a fault indicator of stator electrical unbalance. A brief explanation of this technique is provided below $[12,40]$.

The components of Park's vector $\left(i_{D}\right.$ and $\left.i_{Q}\right)$ for a set of three phase balanced currents are computed by applying the Clarke transformation and given by:

$$
\begin{gathered}
i_{D}=\left(\frac{\sqrt{2}}{\sqrt{3}}\right) i_{A}-\left(\frac{1}{\sqrt{6}}\right) i_{B}-\left(\frac{1}{\sqrt{6}}\right) i_{C} \\
i_{Q}=\left(\frac{1}{\sqrt{2}}\right) i_{B}-\left(\frac{1}{\sqrt{2}}\right) i_{C}
\end{gathered}
$$

where $i_{D}$ and $i_{Q}$ are the current components of Park's vector in direct and quadrature axes, respectively; and $i_{A}, i_{B}$, and $i_{C}$ are balanced line currents in phases $A, B$ and $C$, respectively.

When the conditions are ideal, the resultant Park circle is a perfect circle, whose center locates at the origin of the coordinates. Considering the wave shape parameters of the balanced line currents $A$, $B$ and $C$, it is obtained:

$$
\begin{aligned}
& i_{D}=\left(\frac{\sqrt{6}}{2}\right) i_{M} \cos (\omega t-\theta) \\
& i_{Q}=\left(\frac{\sqrt{6}}{2}\right) i_{M} \sin (\omega t-\theta)
\end{aligned}
$$

where $i_{M}$ is the peak value of the line current; $\omega$ is the angular frequency, in (rad/s); $\theta$ is the initial phase angle, in (rad); and $t$ is the time variable.

When the conditions are not ideal, for instance, when an electrical unbalance is present, the Park circle presents some distortion. Thus, the currents contain direct and inverse sequence components, which can be represented as:

$$
\begin{gathered}
i_{A}=i_{d} \cos \left(\omega t-\theta_{d}\right)+i_{i} \cos \left(\omega t-\gamma_{i}\right) \\
i_{B}=i_{d} \cos \left(\omega t-\theta_{d}-\frac{2 \pi}{3}\right)+i_{i} \cos \left(\omega t-\gamma_{i}+\frac{2 \pi}{3}\right) \\
i_{C}=i_{d} \cos \left(\omega t-\theta_{d}+\frac{2 \pi}{3}\right)+i_{i} \cos \left(\omega t-\gamma_{i}-\frac{2 \pi}{3}\right)
\end{gathered}
$$

where $i_{d}$ is the maximum value of the direct sequence current; $i_{i}$ is the maximum value of inverse sequence current; $\theta_{d}$ is the initial phase angle of the direct sequence current, in (rad); and $\gamma_{i}$ is the initial phase angle of the inverse sequence current, in (rad). By substituting (5) in (3), it is obtained:

$$
\begin{aligned}
& i_{D}=\left(\frac{\sqrt{3}}{\sqrt{2}}\right)\left(i_{d} \cos \left(\omega t-\theta_{d}\right)+i_{i} \cos \left(\omega t-\gamma_{i}\right)\right) \\
& i_{Q}=\left(\frac{\sqrt{3}}{\sqrt{2}}\right)\left(i_{d} \sin \left(\omega t-\theta_{d}\right)-i_{i} \sin \left(\omega t-\gamma_{i}\right)\right)
\end{aligned}
$$

In order to obtain the resultant signal for analysis, the computation of the square of Park's vector module is executed:

$$
i_{D}^{2}+i_{Q}^{2}=\left(\frac{3}{2}\right)\left(i_{d}^{2}+i_{i}^{2}\right)+3 i_{d} i_{i} \cos \left(2 \omega t-\theta_{d}-\gamma_{i}\right)
$$

Finally, the FFT algorithm is applied to the square of the Park's vector module. In the presence of electrical unbalance, the resulting spectrum contains a DC level and a component located at twice the power line frequency. This component is defined as the EPVA electrical unbalance fault pattern.

As a final comment, the procedure has been explained for current signals, but the same can be used for voltage signals.

\section{ESA Fault Patterns for Synchronous Generators}

This section presents ESA fault patterns for SGs that will be used in the proposed methodology of this work. These patterns are valid for different types of SGs and have been presented in the literature and proved experimentally [41]. An observation is that both voltage (VSA or EPVA) and current (CSA or EPVA) signatures must be analyzed. 


\subsection{Rotor Winding Inter-Turn Short Circuit}

SG rotor winding inter-turn short circuit fault presents the characteristics: increase of rotor current, an increase of winding temperature, distortion of voltage waveform, unusual vibration, and possibility of mechanical faults occurring.

The proposed ESA fault patterns are rotor rotation frequency pattern and even harmonics on the electrical signature.

The rotor rotation frequency is defined by the monitoring of line frequency with sidebands in integer multiples of rotor rotation frequency. The rotor rotates at synchronous speed. Thus, the rotor rotation frequency is given by:

$$
f_{r}=\frac{f_{1}}{P}
$$

where $f_{r}$ is the rotor rotation frequency, $f_{1}$ is the line frequency, and $P$ is the number of pole pairs. A note is that the expression "pole pairs" is used to refer to the "physical" number of pole pairs in the rotor of the SG and this is valid for all the times this expression appears in this paper. Thus, the rotation frequency pattern is given by $[6,13,19,38]$ :

$$
f_{p f r}=f_{1} \pm k \cdot f_{r}
$$

where $f_{p f r}$ are the spectral components analyzed for SG rotor mechanical problems and $k$ is a positive integer.

Figure 1a illustrates the rotor rotation frequency, which must be analyzed on voltage and current signatures.

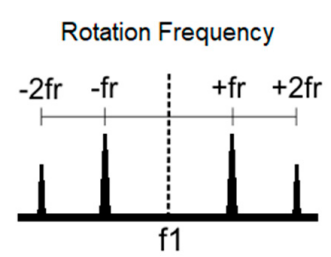

(a)

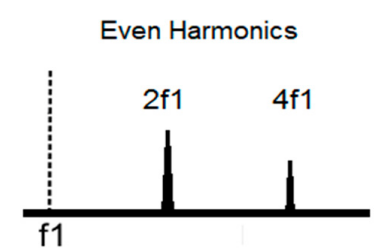

(b)

Figure 1. Fault patterns: (a) rotor rotation frequency (pattern for rotor winding inter-turn short circuit-electrical fault, and for rotor mechanical faults); (b) even harmonics (pattern for rotor winding inter-turn short circuit-electrical fault).

Another proposed fault pattern for this type of fault is the analysis of even harmonics $\left(f_{\text {php }}\right)$ in the electrical signature, which are given by $[13,19,33,34]$ :

$$
f_{p h p}=2 \cdot k \cdot f_{1}
$$

This pattern must be analyzed on voltage and current signatures and is illustrated in Figure $1 \mathrm{~b}$.

\subsection{Stator Winding Inter-Turn Short Circuit}

Another type of fault that SGs can suffer is stator winding inter-turn short circuit, whose characteristics are: the emergence of pulsating currents and generation of rotating fields in the opposite direction of the original one.

The proposed fault patterns for this fault are the zero sequence harmonics (mainly the third harmonic) in the electrical signature, and the EPVA electrical unbalance pattern [12,13].

The zero sequence harmonics fault pattern $\left(f_{\text {phsz }}\right)$ is given by:

$$
f_{\text {phsz }}=3 \cdot k \cdot f_{1}
$$

This fault pattern must be analyzed in voltage and current signatures and is illustrated in Figure 2a. 


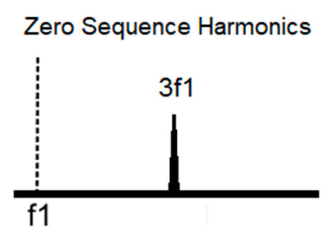

(a)

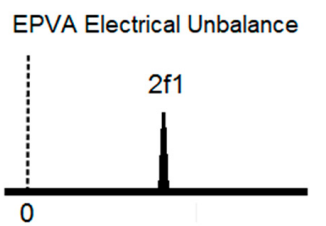

(b)

Figure 2. Fault patterns: (a) zero sequence harmonics; (b) EPVA electrical unbalance (patterns for stator electrical unbalance-electrical fault).

The EPVA electrical unbalance pattern $\left(f_{\text {epva }}\right)$ is defined as the component of twice the line frequency in the EPVA spectrum of voltage and current, being represented as:

$$
f_{\text {epva }}=2 \cdot f_{1}
$$

Figure $2 b$ illustrates this pattern, which must be analyzed on EPVA voltage and current signatures.

As a note, these patterns are also valid for other faults that result in stator electrical unbalance (phase-to-neutral short circuit, phase-to-phase short circuit, open circuit fault).

\subsection{Rotor Mechanical Faults}

Rotor mechanical faults include mechanical misalignment, mechanical unbalance, static airgap eccentricity, and dynamic airgap eccentricity. Some effects of these faults include: an increase in vibration, higher electromagnetic stress, an increase of unbalanced magnetic pull (UMP), increase of bear wear, and rotor and stator rubbing.

The fault pattern proposed for these faults is the rotor rotation frequency on voltage and current signatures, as illustrated in Figure 1a, because these faults also cause an increase in the magnitude of this component $[25,29,38]$.

\section{Peculiarities of Electrical Signature Analysis of Synchronous Generators}

The last section presented ESA fault patterns for SGs. However, it is important to contextualize that ESA has been largely applied to fault detection of induction motors in an industrial environment and the application to SGs is more recent and entails some peculiarities. Thus, this section compiles some important issues related to ESA application to SGs condition monitoring.

\subsection{Signal Analysis}

The first peculiarity of ESA application to fault detection of SGs is related to the choice of signals to be analyzed because both voltages and currents are outputs of these machines. In the literature, ESA experts recommend to analyze the stator voltage and current signals. In the case of isolated SGs, the analysis should focus on the voltage signature (VSA and EPVA) and relate to the current signature (CSA and EPVA). If the component magnitude under analysis is greater in voltage than in current (in $\mathrm{dB}$ ), one may suppose that there is an incipient fault in the SG. Otherwise, one may suppose that the incipient fault is in the load [28].

These considerations are valid for isolated SGs. This work assumed that for SGs interconnected to power systems, the focus should be on current signature (CSA and EPVA). This because if an SG is connected to an infinite bus, then the system voltage would prevail over the SG generated voltage.

\subsection{Discrimination of Mechanical and Electrical Rotor Faults on Fault Patterns}

A second peculiarity is related to the discrimination of faults whose effects occur in the same fault pattern. As one may note, the rotor rotation frequency pattern is indicative of rotor mechanical problems, and rotor winding inter-turn short circuit $[11,13,19,25,29]$. Thus, by analyzing only this fault pattern, it is possible to detect rotor problems, but not to distinguish if it is an electrical or a mechanical 
problem. In order to get a reliable fault diagnosis for SGs based on ESA, it would be necessary to separate the effects of electrical and mechanical faults in the rotation frequency components.

A methodology based on the analysis of symmetrical components to distinguish SG rotor faults has been proposed in [9]. This approach focused on the first right sideband of the rotation frequency, presenting a theoretical analysis and experimental results. The cited work found that the rotor winding inter-turn short circuit fault caused the increase of positive (mainly), negative, and zero sequence magnitudes of the rotation frequency's first right sideband. On the other hand, the rotor mechanical unbalance caused the increase only of the positive sequence magnitude of the rotation frequency's first right sideband. Thus, these findings should be associated with the rotor rotation frequency fault pattern, to provide a better fault diagnosis using ESA.

\subsection{Two-Pole Synchronous Generators}

The SGs at hydroelectric power plants are usually built with a salient pole for two or more pole pairs (low-speed or hydrogenerators), and SGs at thermal and nuclear power plants are normally built with a non-salient pole for one or two pole pairs (high speed or turbogenerators) [42]. As the proposed ESA methodology is applicable for both types of SGs, a last peculiarity emerges for the specific case of two-pole SGs. In this case, the rotation frequency is equal to the line frequency (fundamental frequency). Thus, the fault patterns match the harmonics of the fundamental frequency. The harmonics in an SG include the intrinsic harmonics due to the structural characteristics of the SGs and the magnetomotive force waveform, harmonics due to non-linear loads fed by the SG (they reflect in the SGs signals because of the armature reaction effect), and harmonics due to possible internal faults of the SGs (for instance, the second harmonic as indicative of rotor faults). In practice, even healthy machines may present even harmonics, and this can confuse the fault diagnosis when using ESA [30-33]. Even harmonics are indicative of rotor winding short circuit and the second harmonic matches the rotation frequency pattern's first right sideband. For a correct fault diagnostic, it is necessary to do an in-depth study about the different harmonics in SG signals and the interactions among them.

A previous study [34] on this issue concluded that the SG intrinsic even harmonics (due to possible internal asymmetry in the machine or mechanical misalignment condition) did not confuse the diagnosis of rotor winding inter-turn short circuit fault by using ESA. The cited work was substantiated by experimental results. However, for future works, it is important to perform experimental tests with non-linear loads at the SG output to analyze the effect of harmonics in ESA fault patterns and their influence on fault detection.

Finally, it is not the scope of this work to approach in depth each cited peculiarity. The main objective was to point them out and show how they have been approached. Moreover, the influence of saturation and power factor in SG fault detection is not addressed, being proposed for future works.

\section{Proposed Methodology for Fault Diagnosis of SGs in Bulk Electric Systems}

This section describes the proposed ESA-based methodology for condition monitoring of SGs, considering the ESA fault patterns and the SGs peculiarities presented in the last sections.

A system has been developed for SGs CBM based on ESA. The system includes two PS TTD-01 differential AC voltage transducers, $2.5 \%$ peak-to-peak error, used to measure two phase-to-phase voltages. Two TT 50-SD differential AC current transducers, 2.0\% peak-to-peak error are used to measure two line-currents. The transducers are installed at the secondary side of the SGs voltage and current transformers, and are accessed through the panels of the generating units (GUs).

The transducers are connected to an acquisition system by National Instruments composed by the Ethernet cDaq-9181 carrier and the NI-9239 module for data acquisition. This system is provided with four channels for simultaneous signal acquisition, and the acquisitions are accomplished with 131072 points each one and $16.67 \mathrm{kHz}$ sample frequency. The analog-to-digital converter resolution is 24 bits.

The acquisition system communicates with a personal computer through a signal analysis software (SAS) developed in C\# to command the acquisitions and perform the signal analysis and the machine 
diagnosis. The set of fault patterns presented in (9)-(12), including the symmetrical components approach described previously, is implemented in the SAS. The SAS is the heart of the proposed system, being the part of the system where the fault patterns and rules presented in Sections 3 and 4 are implemented to perform fault detection and identification, even for an SG connected to the grid.

The first step of the proposed methodology is the acquisition of the machine's electrical signals. Once acquired, the signals are processed, the FFT algorithm is applied to get the signal spectral components, other signal processing techniques or post-processing analysis are performed, the database is fed with this information, and the SAS performs the analysis. Thus, the electrical signatures can be analyzed in a qualitative and quantitative way, especially considering the predefined fault patterns. Figure 3 presents a schematic diagram of the described ESA-based methodology for SGs CBM.

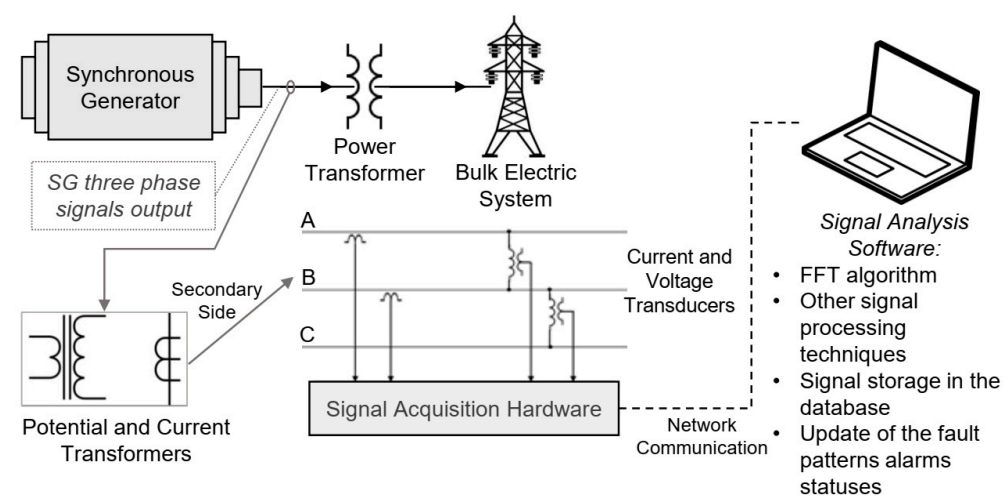

Figure 3. Electrical signature analysis (ESA) based methodology for condition-based maintenance of synchronous generators (SGs).

The described process is performed continuously over time. The system can be programmed to acquire a number of signals in predefined time intervals, each day. Then, a database is created and continuously fed. The analysis for fault detection is performed considering the database stored from the system installation time until the moment of analysis. This is performed by analyzing the trend curves of the fault patterns magnitudes. Thus, it is possible to note any abnormal increase in a component magnitude and its evolution over time.

The analysis is accomplished by setting alarms for the fault pattern's component's magnitudes. The alarm levels are obtained empirically, according to maintenance specialist expertise. For means of complementation, the analysis can also be comparative. When there are data of the machine in a healthy condition (baseline), the analysis is comparative with the baseline condition. However, when the baseline is not available, and there are equal machines (of the same model and nameplate data) being monitored, the analysis can be comparative between the machines. In both cases, the selected data for analysis must be in the same operation range, considering the machine voltage and load level.

The SAS presents features so that the user can access screens with the fault pattern's trend curves and spectrum of a selected electrical signal in order to perform an in-depth analysis. The SAS also provides a report containing the general condition of the SG, including a traffic light (red, yellow or green) indicating the condition regarding the monitored faults. This is automatically updated when the database receives a new signal acquisition, including the summary of the report, which can be accessed on the main screen of the SAS.

It is important to reinforce that the fault types are detected and identified considering the fault patterns and recommendations presented in the Sections 3 and 4, and these fault patterns are comprehensive and include faults normally able to be detected in a predictive maintenance system. The approach of other faults in these systems can be proposed for future works. Finally, with the support of the described system, the decision to stop a machine or not due to indications from the electrical signature will be performed by the maintenance staff and requires some experience and knowledge of the process and the machine's behavior history [7]. 


\section{Results of Fault Detection in In-Service SGs in Bulk Electric Systems by Using ESA}

This section presents results of fault detection in in-service SGs in a bulk electric system by using ESA.

The developed methodology of SG CBM based on ESA has been applied to in-service generating units (GUs) of a Brazilian hydroelectric power plant called Goiandira. This power plant is located at Brazilian state of Goias and has two GUs (GU\#1 and GU\#2) with the following ratings: power = $15 \mathrm{MW}$, stator voltage $=13,800 \mathrm{~V}$, stator current $=627.6 \mathrm{~A}$, frequency $=60 \mathrm{~Hz}, 26$ poles (salient-pole rotor), excitation voltage $=190 \mathrm{~V}$, excitation current $=480 \mathrm{~A}$, rotor rotation speed $=276.9 \mathrm{rpm}$.

Two types of faults were detected in this power plant by using the proposed ESA based methodology, as described as follows.

\subsection{Early Stage of Stator Phase-to-Phase Short Circuit}

Firstly, the power plant personnel had reported that GU\#1 presented a covered winding coil. This is because a short circuit had occurred between turns 179 of phase 1 and 184 of phase 2 (the level of severity had not been informed) and the solution adopted to mitigate the problem was the isolation of the stator coils, which caused stator electrical unbalance. Figure 4 presents the part of the GU\#1 stator winding where the fault happened. Thus, the electrical signatures were analyzed to search for fault indicators for this type of fault. The fault pattern of EPVA electrical unbalance, as described in (12), has been analyzed.

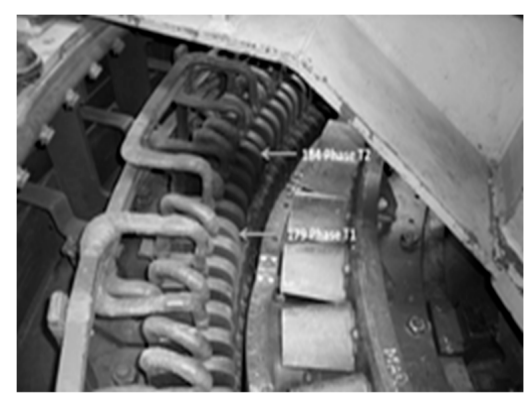

(a)

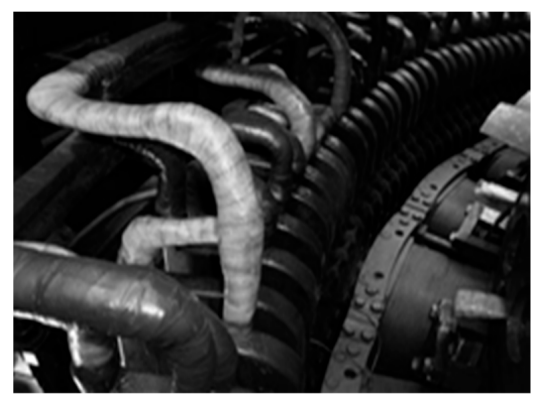

(b)

Figure 4. Fault indication and mitigation in the stator winding of generating unit (GU) \#1: (a) fault indication; (b) fault mitigation.

Here it is important to point out that as a data history of GU\#1 and GU\#2 before the fault was not available, the analysis was accomplished as a comparison between the two GUs, considering the database stored from the installation time until the analysis moment. As explained in the last section, the data used in this analysis must be in the same operation range, considering the load condition. The data of the GUs were selected in a range between $89.2 \%$ and $92.4 \%$ of the rated load, considering the current as reference, and the levels of voltage were similar between the GUs. As the GUs were in a similar level of operation, considering the load condition, the selected data were appropriate for an ESA comparative analysis.

Considering the current and voltage signals in the database and the EPVA computed for them by the SAS, Figure 5 presents the trend curves of the EPVA electrical unbalance in voltage and current signatures of the GUs at Goiandira. For this analysis, the daily average of data has been considered, and this has also been performed for all the trend curves presented in this section. It can be noticed that, for both GUs, the voltage unbalance was about $0.4 \%$. The current unbalance was between $0.5 \%$ and $1.5 \%$ for GU\#2 and between $2.5 \%$ and $3.0 \%$ for GU\#1. Thus, GU\#1 presented a larger electrical unbalance at the EPVA current signature than GU\#2. Thus, the fault indicator of the covered coil was detected in the EPVA electrical unbalance fault pattern.

In order to verify if the data sets of EPVA electrical unbalance of current signature of the GUs were statistically different and reinforce the ESA diagnosis effectiveness, a two-sample t-test has been 
performed [43] using Minitab software. The data used for the hypothesis testing were the percentage values of electrical unbalance of current signals in the period of analysis. Table 1 presents the results from the two-sample $t$-test for the fault pattern in analysis.

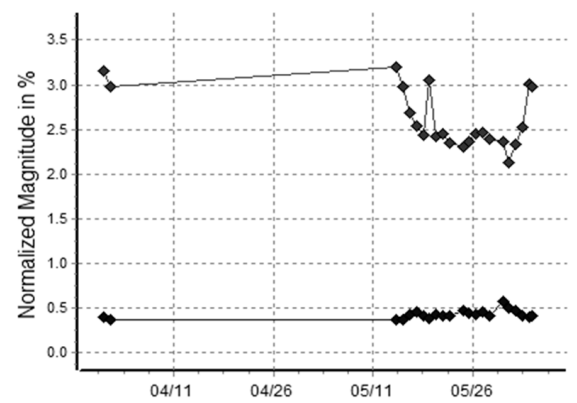

(a)

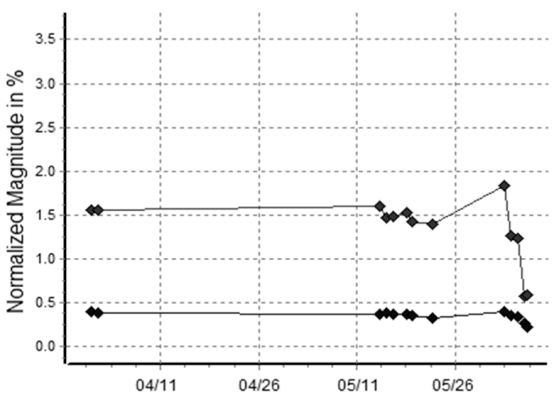

(b)

Figure 5. Trend of the Extended Park's vector approach (EPVA) electrical unbalance of voltage (lower curve) and current (upper curve) signatures for GUs at Goiandira power plant: (a) GU\#1; (b) GU\#2.

Table 1. Results of the two-sample t-test for the EPVA electrical unbalance at current signature.

\begin{tabular}{ccccc}
\hline GU & $\begin{array}{c}\text { Number of } \\
\text { Samples }\end{array}$ & Mean & $\begin{array}{c}\text { Standard } \\
\text { Deviation }\end{array}$ & Standard Error of the Mean \\
\hline GU\#1 & 117 & 2.535 & 0.329 & 0.030 \\
GU\#2 & 46 & 1.35 & 0.410 & 0.060 \\
\hline
\end{tabular}

Estimated difference: 1.1842

Confidence interval of $95 \%$ for the difference: $(1.0493 ; 1.3191)$

$\mathrm{t}$-Test of the difference $=0($ vs not $=): p$-value $=0.000$

From Table 1, it can be concluded that the data set of the EPVA electrical unbalance at current signature of GU\#1 is statistically different from the corresponding data set of GU\#2, because $p$-value < 0.05 . The estimated difference is that the mean of the component magnitudes of GU\#1 is $1.1842 \%$ above the mean of the component magnitudes of GU\#2. This result evidences the fault indicator of covered coil.

Figure 6 presents, for illustration purposes, examples of the EPVA electrical unbalance of current and voltage signatures of GUs \#1 and \#2 of Goiandira power plant. This was performed by choosing an arbitrary signal acquisition for each GU and considering the FFT computed by the SAS. The components are normalized in relation to the fundamental frequency magnitude. By comparing the spectra of Figure $6 \mathrm{a}, \mathrm{b}$, one can notice a significant difference between the component magnitudes of GUs \#1 and \#2, mainly in the EPVA current signature, which evidences the fault indicator of covered coil.

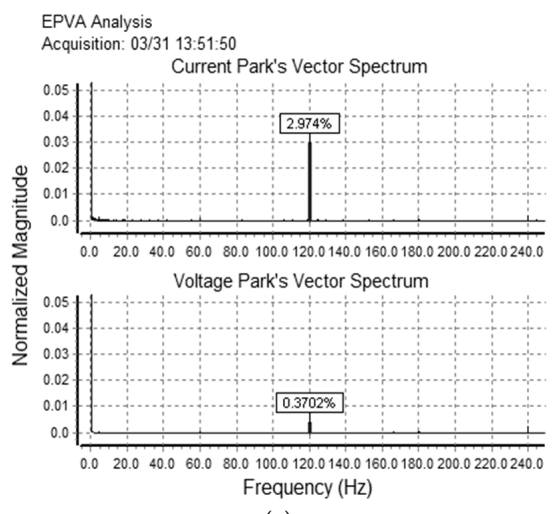

(a)

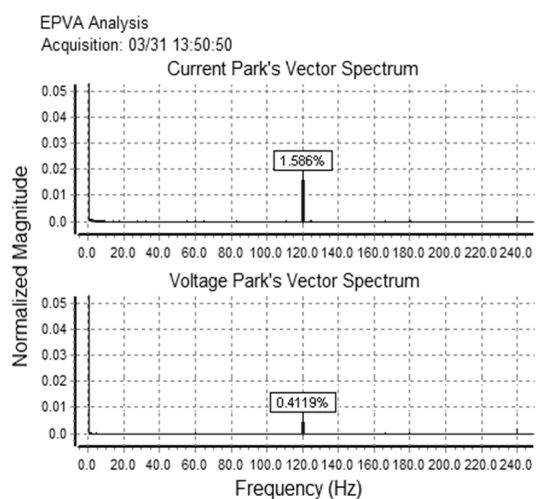

(b)

Figure 6. EPVA electrical unbalance of current and voltage signatures of the Goiandira GUs: (a) GU\#1; (b) GU\#2. 


\subsection{Mechanical Misalignment}

During the performed analysis, the rotation frequency fault pattern, as presented in (9), was also noteworthy. This fault pattern is indicative of rotor mechanical problems. For the purpose of analysis, the same current and voltage data selected in the last section have been considered in the present section.

Considering the current and voltage signals in the database and the signatures computed by the SAS, Figure 7 presents the trend curves of the rotation frequency of the voltage and current signatures of GUs at Goiandira power plant, considering the average level of the components. It can be noticed that the component's magnitudes were about $-90 \mathrm{~dB}$ for GU\#1 and $-95 \mathrm{~dB}$ for GU\#2, for voltage signals. The component's magnitudes were about $-70 \mathrm{~dB}$ for GU\#1 and $-82 \mathrm{~dB}$ for GU\#2, for current signals.

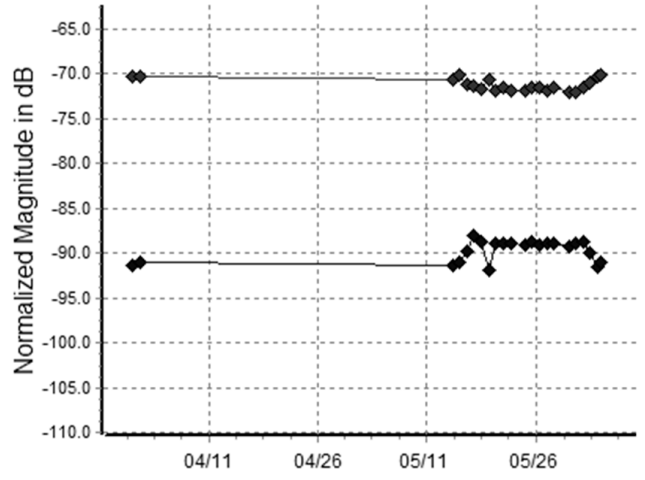

(a)

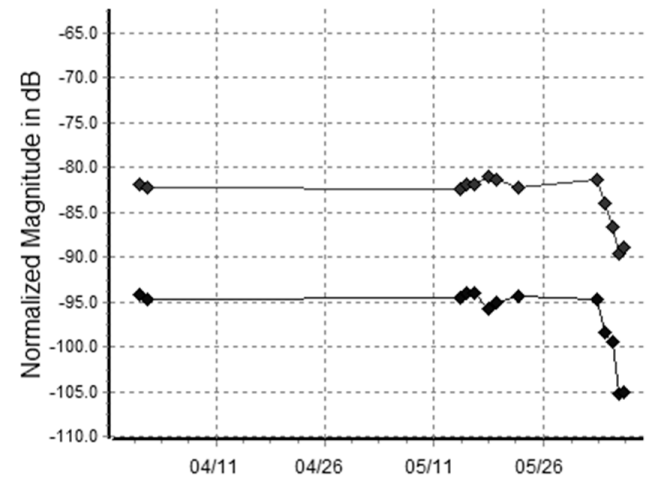

(b)

Figure 7. Trend of rotation frequency pattern of voltage (lower curve) and current (upper curve) signatures for GUs at Goiandira power plant: (a) GU\#1; (b) GU\#2.

There is a significant difference between the rotation frequency component's magnitudes of GU\#1 and GU\#2, mainly in current signature, and GU\#1 presents higher magnitudes in relation to GU\#2. This fault pattern is indicative of rotor winding inter-turn short circuit or rotor mechanical problems. After the analysis, the power plant personnel reported that GU\#1 presented "dogleg" condition, which is an angular mechanical misalignment between the turbine shaft and the generator rotor shaft. Thus, the hypothesis raised by the analysis has been confirmed.

In order to verify if the data sets of rotation frequency of current signature of GUs were statistically different and reinforce the ESA diagnosis effectiveness, a two-sample t-test has been performed [43] using Minitab software. The data used for the hypothesis testing were the rotation frequency component's magnitudes in $\mathrm{dB}$ of current signals in the period of analysis. Table 2 presents the results for the two-sample t-test for the fault pattern in question.

Table 2. Results of two-sample t-test for rotation frequency of current signature.

\begin{tabular}{ccccc}
\hline GU & $\begin{array}{c}\text { Number of } \\
\text { Samples }\end{array}$ & Mean & $\begin{array}{c}\text { Standard } \\
\text { Deviation }\end{array}$ & $\begin{array}{c}\text { Standard Error of } \\
\text { the Mean }\end{array}$ \\
\hline GU\#1 & 117 & -71.357 & 0.678 & 0.063 \\
GU\#2 & 46 & -83.520 & 3.430 & 0.510 \\
\hline \multicolumn{4}{c}{ Estimated difference: 12.165} \\
& Confidence interval of 95\% for the difference: $(11.140 ; 13.190)$ \\
& t-Test of the difference $=0$ (vs not $=): p$-value $=0.000$ \\
\hline
\end{tabular}

It can be concluded that the data set of the rotation frequency component's magnitudes of GU\#1 is statistically different from the corresponding data set of GU\#2, because $p$-value $<0.05$. The estimated difference is that the GU\#1 component magnitudes mean is $12.165 \mathrm{~dB}$ above the mean of 
the component magnitudes of GU\#2. This result provided evidence for the fault indicator of rotor mechanical misalignment.

Figure 8 presents, for illustration purposes, examples of rotation frequency components of the current and voltage signatures of GU\#1 and GU\#2 at Goiandira power plant. These were signal acquisitions chosen arbitrarily to show the signatures computed by the SAS. There is a significant difference between the components of GU\#1 and GU\#2, mainly in current signature, and the component's magnitudes of GU\#1 are higher than GU\#2. This is evidence of the fault indicator of rotor mechanical misalignment.

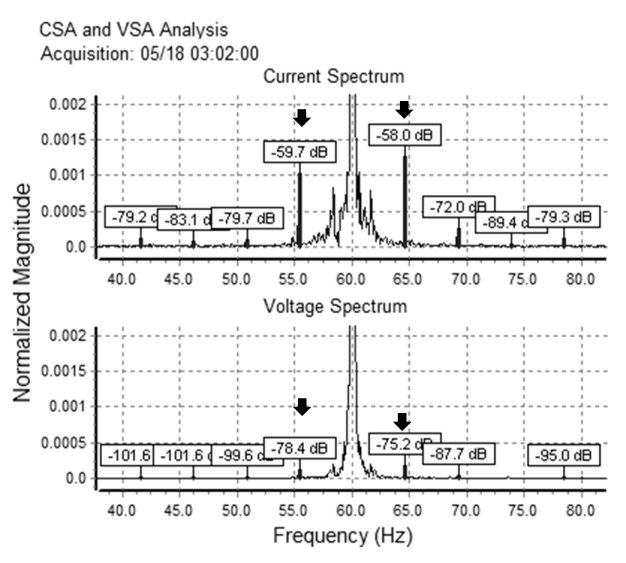

(a)

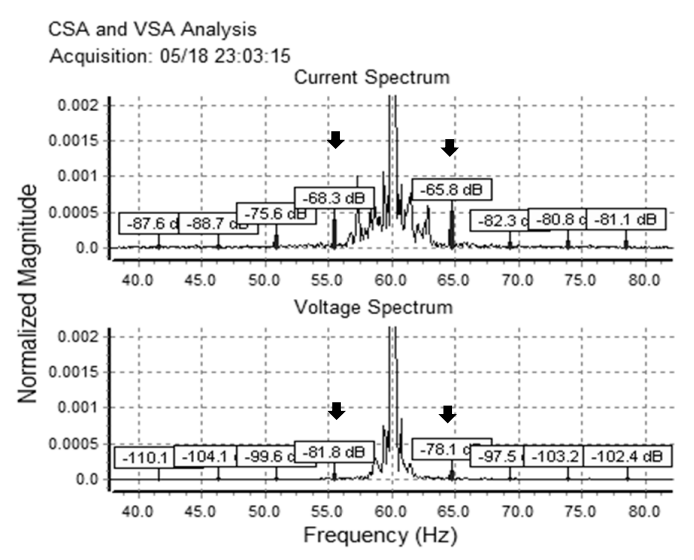

(b)

Figure 8. Rotation frequency of the current and voltage signatures of Goiandira GUs: (a) GU\#1; (b) GU\#2.

\subsection{Final Remarks}

It is important to reinforce that the proposed system can detect electrical and mechanical faults, including those presented in Section 3. The current section has focused only on two types of faults (stator electrical unbalance and mechanical misalignment) because these were the faults detected in practice in the in-service SG in the monitored hydroelectric power plant. When working in a laboratory environment, it is possible to simulate different types of faults in a machine and get results covering all of them [3]. However, when considering a power plant application, the studied types of faults will not always occur during the selected period of monitoring and analysis. Finally, the results obtained in a power plant are very valuable, because this environment is concerned with monitoring and is subjected to diverse conditions of bulk power system.

\section{Conclusions}

This paper has presented a study on ESA for condition monitoring of SGs in bulk electric systems. The paper has presented a methodology for SG predictive maintenance by using ESA and has also addressed peculiarities in the application of this technique to fault detection in wound rotor SGs. The main contribution of this work is the practical results of ESA for fault detection in an in-service SG connected to a power system.

The detected faults were an early stage of stator phase-to-phase short circuit, detected in the EPVA electrical unbalance pattern, and mechanical misalignment, detected in the rotation frequency pattern. The results show the potential of applying ESA to fault detection in SGs interconnected to a power system. Moreover, it has been shown that in this case, the emphasis of ESA must be on CSA. This is because the faults were more evident through the analysis of fault patterns in current signatures than in voltage signatures.

It may be proposed for future works to improve the automatisms and diagnostics of the system by using artificial intelligence techniques and expand the possible monitored conditions beyond fault detection and identification. 
Author Contributions: C.P.S., C.F. and G.L.-T. conceived and designed the experiments; C.P.S., L.E.B.d.S., C.F., E.L.B., and L.E.d.L.d.O. performed the experiments; C.P.S., W.C.S., C.F., and G.L.-T. analyzed the data; L.E.B.d.S., E.L.B., L.E.d.L.d.O., and B.S.T. contributed analysis tools; and C.P.S., W.C.S. and G.L.-T. wrote the paper.

Acknowledgments: The authors would like to thank the National Council for Scientific and Technological Development (CNPq), the Coordination for the Improvement of Higher Education Personnel (CAPES), and the Brazilian Electricity Regulatory Agency Research and Development (ANEEL R\&D) for supporting this project.

Conflicts of Interest: The authors declare no conflict of interest.

\section{Nomenclature}

\section{Abbreviations}

CBM Condition-based maintenance

CSA Current signature analysis

DFT Discrete Fourier Transform

ESA Electrical signature analysis

EPVA Extended Park's vector approach

FFT Fast Fourier Transform

GU\#1 Generating unit \#1

GU\#2 Generating unit \#2

GUs Generating units

SAS Signal analysis software

SGs Synchronous generators

UMP Unbalanced magnetic pull

VSA Voltage signature analysis

\section{Parameters}

$f_{1} \quad$ Power line frequency

$f_{c} \quad$ Specific fault characteristic frequency

$f_{e} \quad$ Fault frequency

$f_{\text {epva }} \quad$ EPVA electrical unbalance pattern

$f_{p f r} \quad$ Spectral components analyzed for SG rotor mechanical problems

$f_{\text {php }} \quad$ Spectral components analyzed for SG even harmonics

$f_{\text {phsz }} \quad$ Zero sequence harmonics fault pattern

$f_{r} \quad$ Rotor rotation frequency

$i_{A} \quad$ Current of phase A

$i_{B} \quad$ Current of phase B

$i_{C} \quad$ Current of phase $C$

$i_{D} \quad$ Direct component of Park's vector

$i_{d} \quad$ Maximum value of the direct sequence current

$i_{i} \quad$ Maximum value of inverse sequence current

$i_{M} \quad$ Peak value of the line current

$i_{Q} \quad$ Quadrature component of Park's vector

$k \quad$ Positive integer value

$m \quad$ DFT index (harmonic order)

$n \quad$ Time-domain index

$N \quad$ Number of samples

$P \quad$ Number of pole pairs

$t \quad$ Time variable

$X_{m} \quad m^{\text {th }}$ DFT coefficient

$x_{n} \quad$ Time-domain list of equally-spaced complex samples

$\gamma_{i} \quad$ Initial phase angle of the inverse sequence current, in (rad)

$\theta \quad$ Initial phase angle, in (rad)

$\theta_{d} \quad$ Initial phase angle of the direct sequence current, in (rad)

$\omega \quad$ Angular frequency, in ( $\mathrm{rad} / \mathrm{s})$ 


\section{References}

1. Monaro, R.M.; Vieira, J.C.M.; Coury, D.V.; Malik, O.P. A Novel Method Based on Fuzzy Logic and Data Mining for Synchronous Generator Digital Protection. IEEE Trans. Power Deliv. 2015, 30, 1487-1495. [CrossRef]

2. Gaona, C.A.P.; Blázquez, F.; Frias, P.; Redondo, M. A Novel Rotor Ground-Fault-Detection Technique for Synchronous Machines With Static Excitation. IEEE Trans. Energy Convers. 2010, 25, 965-973. [CrossRef]

3. Mendonça, P.L.; Bonaldi, E.L.; de Oliveira, L.E.L.; Lambert-Torres, G.; Borges da Silva, J.G.; Borges da Silva, L.E.; Salomon, C.P.; Santana, W.C.; Shinohara, A.H. Detection and modelling of incipient failures in internal combustion engine driven generators using Electrical Signature Analysis. Electr. Power Syst. Res. 2017, 149, 30-45. [CrossRef]

4. Chothani, N.G. Development and Testing of a New Modified Discrete Fourier Transform-based Algorithm for the Protection of Synchronous Generator. Electr. Power Compos. Syst. 2016, 44, 1564-1575. [CrossRef]

5. Safari-Shad, N.; Franklin, R.; Negahdari, A.; Toliyat, H.A. Adaptive 100\% Injection-Based Generator Stator Ground Fault Protection With Real-Time Fault Location Capability. IEEE Trans. Power Deliv. 2018, 33, 2364-2372. [CrossRef]

6. Tavner, P.J. Review of condition monitoring of rotating electrical machines. IET Electr. Power Appl. 2008, 2, 215-247. [CrossRef]

7. Bonaldi, E.L.; de Oliveira, L.E.L.; Borges da Silva, J.G.; Lambert-Torres, G.; Borges da Silva, L.E. Predictive maintenance by electrical signature analysis to induction motors. In Induction Motors-Modelling and Control; Araujo, R., Ed.; InTech: Rijeka, Croatia, 2012; pp. 487-520. [CrossRef]

8. Merizalde, Y.; Hernández-Callejo, L.; Duque-Perez, O. State of the Art and Trends in the Monitoring, Detection and Diagnosis of Failures in Electric Induction Motors. Energies 2017, 10, 1056. [CrossRef]

9. Salomon, C.P.; Santana, W.C.; Borges da Silva, L.E.; Lambert-Torres, G.; Bonaldi, E.L.; de Oliveira, L.E.L.; Borges da Silva, J.G. Induction Motor Efficiency Evaluation using a New Concept of Stator Resistance. IEEE Trans. Instrum. Meas. 2015, 64, 2908-2917. [CrossRef]

10. Reljic, D.; Jerkan, D.; Marcetic, D.; Oros, D. Broken Bar Fault Detection in IM Operating Under No-Load Condition. Adv. Electr. Comput. Eng. 2016, 16, 63-70. [CrossRef]

11. Salomon, C.P.; Santana, W.C.; Borges da Silva, L.E.; Lambert-Torres, G.; Bonaldi, E.L.; de Oliveira, L.E.L. Comparison among Methods for Induction Motor Low-Intrusive Efficiency Evaluation Including a New AGT Approach with a Modified Stator Resistance. Energies 2017, 11, 691. [CrossRef]

12. Cruz, S.M.A.; Cardoso, A.J.M. Stator winding fault diagnosis in three-phase synchronous and asynchronous motors, by the extended park's vector approach. IEEE Trans. Ind. Appl. 2001, 37, 1227-1233. [CrossRef]

13. Sottile, J.; Trutt, F.C.; Leedy, A.W. Condition Monitoring of Brushless Three-Phase Synchronous Generators With Stator Winding or Rotor Circuit Deterioration. IEEE Trans. Ind. Appl. 2006, 42, 1209-1215. [CrossRef]

14. Fayazi, M.; Haghjoo, F. Turn to turn fault detection and classification in stator winding of synchronous generators based on terminal voltage waveform components. In Proceedings of the 9th Power Systems Protection \& Control Conference (PSPC2015), Tehran, Iran, 14-15 January 2015; pp. 36-41. [CrossRef]

15. Nadarajan, S.; Panda, S.K.; Bhangu, B.; Gupta, A.K. Hybrid Model for Wound-Rotor Synchronous Generator to Detect and Diagnose Turn-to-Turn Short-Circuit Fault in Stator Windings. IEEE Trans. Ind. Electron. 2015, 62, 1888-1900. [CrossRef]

16. Nadarajan, S.; Panda, S.K.; Bhangu, B.; Gupta, A.K. Online Model-Based Condition Monitoring for Brushless Wound-Field Synchronous Generator to Detect and Diagnose Stator Windings Turn-to-Turn Shorts Using Extended Kalman Filter. IEEE Trans. Ind. Electron. 2016, 63, 3228-3241. [CrossRef]

17. Shuting, W.; Heming, L.; Yonggang, L.; Fanchao, M. Analysis of stator winding parallel-connected branches circulating current and its application in generator fault diagnosis. In Proceedings of the IEEE 40th Industry Applications Conference (IEEE IAS 2005), Kowloon, Hong Kong, China, 2-6 October 2005; pp. 42-45. [CrossRef]

18. Na, Y.; Yonggang, L.; Tianming, F.; Zhiqian, Y. A study of inter turn short circuit fault in turbogenerator rotor winding based on single-end fault information and wavelet analysis method. In Proceedings of the Eighth International Conference on Electrical Machines and Systems (EMS 2005), Nanjing, China, 27-29 September 2005; pp. 2211-2215. [CrossRef] 
19. Yucai, W.; Yonggang, L.; Heming, L. Diagnosis of turbine generator typical faults by shaft voltage. In Proceedings of the 2012 IEEE Industry Applications Society Annual Meeting (IEEE IAS 2012), Las Vegas, NV, USA, 7-11 October 2012; pp. 1-6. [CrossRef]

20. Yucai, W.; Yonggang, L. Diagnosis of short circuit faults within turbogenerator excitation winding based on the expected electromotive force method. IEEE Trans. Energy Convers. 2016, 31, 706-713. [CrossRef]

21. Toliyat, H.A.; Al-Nuaim, N.A. Simulation and detection of dynamic air-gap eccentricity in salient-pole synchronous machines. IEEE Trans. Ind. Appl. 1999, 35, 86-93. [CrossRef]

22. Bruzzese, C.; Rossi, A.; Santini, E.; Benucci, V.; Millerani, A. Ship brushless generator shaft misalignment simulation by using a complete mesh-model for machine voltage signature analysis (MVSA). In Proceedings of the 2009 IEEE Electric Ship Technologies Symposium (ESTS 2009), Baltimore, MA, USA, 20-22 April 2009; pp. 113-118. [CrossRef]

23. Joksimovic, G.; Bruzzese, C.; Santini, E. Static eccentricity detection in synchronous generators by field current and stator voltage signature analysis-Part I: Theory. In Proceedings of the XIX International Conference on Electrical Machines (ICEM 2010), Rome, Italy, 6-8 September 2010; pp. 1-6. [CrossRef]

24. Bruzzese, C. Diagnosis of Eccentric Rotor in Synchronous Machines by Analysis of Split-Phase Currents-Part II: Experimental Analysis. IEEE Trans. Ind. Electron. 2014, 61, 4206-4216. [CrossRef]

25. Ilamparithi, T.; Nandi, S.; Subramanian, J. A disassembly-free offline detection and condition monitoring technique for eccentricity faults in salient-pole synchronous machines. IEEE Trans. Ind. Appl. 2015, 51, 1505-1515. [CrossRef]

26. Salah, M.; Bacha, K.; Chaari, A.; Benbouzid, M.E.H. Brushless three-phase synchronous generator under rotating diode failure conditions. IEEE Trans. Energy Convers. 2014, 29, 594-601. [CrossRef]

27. Cui, J.; Tang, J.; Shi, G.; Zhang, Z. Generator rotating rectifier fault detection method based on stacked auto-encoder. In Proceedings of the 2017 IEEE Workshop on Electrical Machines Design, Control and Diagnosis (WEMDCD 2017), Nottingham, UK, 20-21 April 2017; pp. 256-261. [CrossRef]

28. Penrose, H. Electrical Motor Diagnostics, 2nd ed.; Success by Design: Old Saybrook, CT, USA, 2008.

29. Sahraoui, M.; Ghoggal, A.; Zouzou, S.E.; Benbouzid, M.E. Dynamic eccentricity in squirrel cage induction motors-Simulation and analytical study of its spectral signatures on stator currents. Simul. Modell. Pract. Theory 2008, 16, 1503-15138. [CrossRef]

30. Leong, M.S.; Hee, L.M.; Kae, G.Y. Turbine Generator Synchronization-Two Case Studies. Sound Vib. 2012, 46, 8-11.

31. Jha, R.K.; Pande, A.S.; Singh, H. Design and Analysis of Synchronous Alternator for Reduction in Harmonics and Temperatureby Short Pitch Winding. Int. J. Emerg. Technol. Adv. Eng. 2013, 3, 651-656.

32. Hao, L.; Wu, J.; Zhou, Y. Theoretical Analysis and Calculation Model of the Electromagnetic Torque of Nonsalient-Pole Synchronous Machines With Interturn Short Circuit in Field Windings. IEEE Trans. Energy Convers. 2015, 30, 110-121. [CrossRef]

33. dos Santos, H.F.; Sadowski, N.; Batistela, N.J.; Bastos, J.P.A. Synchronous Generator Fault Investigation by Experimental and Finite Element Procedures. IEEE Trans. Magn. 2016, 52, 1-4. [CrossRef]

34. Salomon, C.P.; Santana, W.C.; Bonaldi, E.L.; de Oliveira, L.E.L.; Borges da Silva, L.E.; Borges da Silva, J.G.; Lambert-Torres, G.; Pellicel, A.; Lopes, M.A.A.; Figueiredo, G.C. A study of electrical signature analysis for two-pole synchronous generators. In Proceedings of the 2017 IEEE Int. Instrumentation and Measurement Technology Conf. (I2MTC 2017), Turin, Italy, 22-25 May 2017; pp. 1-6. [CrossRef]

35. Gopinath, R.; Santhosh Kumar, C.; Ramachandran, K.I.; Upendranath, V.; Sai Kiran, P.V.R. Intelligent fault diagnosis of synchronous generators. Expert Syst. Appl. 2016, 45, 142-149. [CrossRef]

36. Moosavi, S.S.; Djerdir, A.; Ait-Amirat, Y.; Khaburi, D.A. ANN based fault diagnosis of permanent magnet synchronous motor under stator winding shorted turn. Electr. Power Syst. Res. 2015, 125, 67-82. [CrossRef]

37. Zhang, X.; Chen, W.; Wang, B.; Chen, X. Intelligent fault diagnosis of rotating machinery using support vector machine with ant colony algorithm for synchronous feature selection and parameter optimization. Neurocomputing 2015, 167, 260-279. [CrossRef]

38. El Hachemi Benbouzid, M. A review of induction motors signature analysis as a medium for faults detection. IEEE Trans. Ind. Electron. 2000, 47, 984-993. [CrossRef]

39. Smith, S.W. The Scientist and Engineer's Guide to Digital Signal Processing, 2nd ed.; California Technical Publishing: San Diego, CA, USA, 1999. 
40. Cruz, S.M.A.; Cardoso, A.J.M. Rotor Cage Fault Diagnosis in Three-Phase Induction Motors by Extended Park's Vector Approach. Electr. Mach. Power Syst. 2000, 28, 289-299. [CrossRef]

41. Salomon, C.P.; Santana, W.C.; Lambert-Torres, G.; Borges da Silva, L.E.; Bonaldi, E.L.; de Oliveira, L.E.L.; Borges da Silva, J.G.; Pellicel, A.; Figueiredo, G.C.; Lopes, M.A.A. Discrimination of Synchronous Machines Rotor Faults in Electrical Signature Analysis based on Symmetrical Components. IEEE Trans. Ind. Appl. 2017, 53, 3146-3155. [CrossRef]

42. Boldea, I. Synchronous Generators_Electrical Generators Handbook; CRC Press: Boca Raton, FL, USA, 2006.

43. Montgomery, D.C.; Runger, G.C. Applied Statistics and Probability for Engineers, 3rd ed.; John Wiley and Sons: New York, NY, USA, 2003.

(C) 2019 by the authors. Licensee MDPI, Basel, Switzerland. This article is an open access article distributed under the terms and conditions of the Creative Commons Attribution (CC BY) license (http://creativecommons.org/licenses/by/4.0/). 